\title{
Genome wide effects of oleic acid on cultured bovine granulosa cells: evidence for the activation of pathways favoring folliculo-luteal transition
}

\author{
Vengala Rao Yenuganti ${ }^{i^{*}}$, Dirk Koczan ${ }^{2}$ and Jens Vanselow ${ }^{3^{*}}$ (D)
}

\begin{abstract}
Background: Metabolic stress, as negative energy balance on one hand or obesity on the other hand can lead to increased levels of free fatty acids in the plasma and follicular fluid of animals and humans. In an earlier study, we showed that increased oleic acid (OA) concentrations affected the function of cultured bovine granulosa cells (GCs). Here, we focus on genome wide effects of increased OA concentrations.

Results: Our data showed that 413 genes were affected, of which 197 were down- and 216 up-regulated. Specifically, the expression of FSH-regulated functional key genes, CCND2, LHCGR, INHA and CYP19A1 and 17- $\beta$ estradiol (E2) production were reduced by OA treatment, whereas the expression of the fatty acid transporter CD36 was increased and the morphology of the cells was changed due to lipid droplet accumulation. Bioinformatic analysis revealed that associated pathways of the putative upstream regulators "FSH" and "Cg (choriogonadotropin)" were inhibited and activated, respectively. Down-regulated genes are over-represented in GO terms "reproductive structure/system development", "ovulation cycle process", and "(positive) regulation of gonadotropin secretion", whereas up-regulated genes are involved in "circulatory system development", "vasculature development", "angiogenesis" or "extracellular matrix/structure organization".

Conclusions: From these data we conclude that besides inhibiting GC functionality, increased OA levels seemingly promote angiogenesis and tissue remodelling, thus suggestively initiating a premature fulliculo-luteal transition. In vivo this may lead to impeded folliculogenesis and ovulation, and cause sub-fertility.
\end{abstract}

Keywords: Gene expression, Free fatty acids, Estradiol, Angiogenesis, Metabolic stress, Cell culture

\footnotetext{
* Correspondence: vengal.ndri@gmail.com; vanselow@fbn-dummerstorf.de

'Animal Biology Department, School of Life Sciences, University of

Hyderabad, Hyderabad, Telagana, India

${ }^{3}$ Institute of Reproductive Biology, Leibniz Institute for Farm Animal Biology

(FBN), Wilhelm-Stahl-Allee 2, 18196 Dummerstorf, Germany

Full list of author information is available at the end of the article
}

(c) The Author(s). 2021, corrected publication 2021. Open Access This article is licensed under a Creative Commons Attribution 4.0 International License, which permits use, sharing, adaptation, distribution and reproduction in any medium or format, as long as you give appropriate credit to the original author(s) and the source, provide a link to the Creative Commons licence, and indicate if changes were made. The images or other third party material in this article are included in the article's Creative Commons licence, unless indicated otherwise in a credit line to the material. If material is not included in the article's Creative Commons licence and your intended use is not permitted by statutory regulation or exceeds the permitted use, you will need to obtain permission directly from the copyright holder. To view a copy of this licence, visit http://creativecommons.org/ licenses/by/4.0/. The Creative Commons Public Domain Dedication waiver (http://creativecommons.org/publicdomain/zero/1. 0/) applies to the data made available in this article, unless otherwise stated in a credit line to the data. 


\section{Background}

Dairy cows frequently suffer from negative energy balance (NEB) after parturition. Under these metabolic conditions, the serum levels of non-esterified fatty acids (NEFAs) become elevated and can negatively affect the reproductive performance [1-3]. Also in obese women, it has been reported that abnormal NEFA levels and lipid dysregulation are associated with fertility problems [4-6]. During NEB in lactating dairy cows, fat from adipose tissue is mobilized to meet the animal's energy requirements. Consequently, levels of free fatty acids (FFAs) like palmitic acid (PA, 16:0), stearic acid (SA, 18: 0 ), oleic acid (OA, 18:1) and of $\beta$-hydroxybutyric acid, increase in the plasma and follicular fluid $[3,7]$ and can negatively affect milk production and cause increased vulnerability to infections, various metabolic diseases and reduced fertility [8-10]. Also short-term fasting increases the levels of different fatty acids especially of OA in the follicular fluid [11]. Various studies showed that high levels of FFAs are indicators of abnormal lipid metabolism and can affect growth, differentiation and metabolism of cells by altering the gene expression levels [12-14]. Also in granulosa cells (GCs) it has been found that free fatty acids like PA, SA and OA affect cell survival in both humans and bovine $[15,16]$. In our previous studies, we showed in a bovine GC culture model that OA affects the cell morphology and reduces expression of genes that are involved in 17- $\beta$-estradiol (E2) production and gonadotropin signalling as CYP19A1, FSHR and LHCGR $[17,18]$. Also the GC identity marker FOXL2 was down-, whereas the marker of sertoli cells SOX9 was up-regulated [19]. Intriguingly, we could show in addition that OA elicited partly opposing effects compared to PA and SA if applied individually [18]. During the present genome-wide approach we selected to study OA effects because it was found at highest concentration in animals after fasting as compared to PA and SA [11] and it was shown to elicit strong and reproducible effects on cultured E2 producing GCs [17, 18].

To elucidate the pathways and upstream molecules that are involved in GC dysfunction under OA treatment we studied effects of OA on global gene expression and analyzed effects on signaling pathways, upstream regulators and biological processes.

\section{Results}

\section{Oleic acid induced differentially expressed genes}

Microarray analysis of OA vs. vehicle treated GCs after 8 days in culture resulted in 413 differentially expressed genes (DEGs, Supplementary Table 1). According to the statistical criteria used (FC $>|1.5|$, ANOVA $p<0.05$, and FDR $\mathrm{q}<0.05)$ OA treated and vehicle treated control samples ( $n=4$ in each group) were clearly separated by hierarchical cluster analysis (Fig. 1). Out of the 413 DEGs, 197 were down- and 216 genes up-regulated. ALDH1A1 (FC6.15) was the most up-regulated gene, whereas $C Y P 19 A 1$ (FC -4.68$)$ was strongly down-regulated by OA (Table 1 ).

\section{Real -time RT-PCR validation of differentially expressed genes}

From the DEGs we selected functionally interesting upregulated (ALDH1A1, CD36, SLC38A4, TGFB2 and PTGS2), down-regulated (CYP19A1, NOS2, SERPINE2, FSHR and LHCGR) and non-regulated genes (CDH1 and CDH2) for validation by real-time RT-PCR. The results clearly indicated similar OA effects after 8 days in culture thus confirming the microarray data (Fig. 2). An additional analysis also including earlier time points $(4,6$ and 8 days in culture) indicated that the transcript abundance of several genes (CYP19A1, FSHR, LHCGR) remarkably increased under control conditions, but not in the presence of OA (Fig. 3). Instead, the abundance of some transcripts was even reduced by OA (CCND2, INHA). The E2 accumulated over time, but was nearly absent in OA treated samples. In contrast, CD36 was only expressed at very low levels under control conditions, but was largely stimulated by OA treatment.

\section{Bioinformatics analysis of differentially expressed genes}

IPA analysis of DEGs predicted that OA might modulate different Upstream Regulators, Canonical Signaling Pathways, and Functions and Diseases. 98 "Upstream Regulators" were affected with z-scores $>|2|$, out of which 74 were activated and 24 inhibited (Supplementary Table 2). OA activated the Upstream Regulators "TGFB1", "Cg (choriogonadotropin)", "Lipopolysaccharide", "Rosiglitazone", "Tgf beta", "NFkB (complex)" and "HIF1A" etc., and inhibited "SB203580", "FSH", "PD98059", "SMAD7", "Y 27632" and "NR5A1" etc.

IPA analysis also predicted many affected Canonical Pathways. Top scores were indicated for "Hepatic Fibrosis / Hepatic Stellate Cell Activation”, "Ovarian Cancer Signaling", "LPS/IL-1 Mediated Inhibition of RXR Function", "Atherosclerosis Signaling" and "LXR/RXR Activation" (Supplementary Table 3).

Moreover IPA analysis of differentially expressed genes predicted 69 possibly affected diseases and functions. The most significant were "Cellular Movement", "Cancer", "Organismal Injury and Abnormalities", "Cardiovascular System Development and Function" and "Organismal Development" (Supplementary Table 4).

Gene Ontology (GO) term analysis using the WebGestalt tool, showed that among others, down-regulated genes were associated with the terms "reproductive structure/system development", "ovulation cycle process" and "regulation of follicle-stimulating hormone secretion" (Table 2 and Supplementary Figure 1). Simultaneously, the analysis of GO terms associated with upregulated genes revealed effects on "circulatory system 


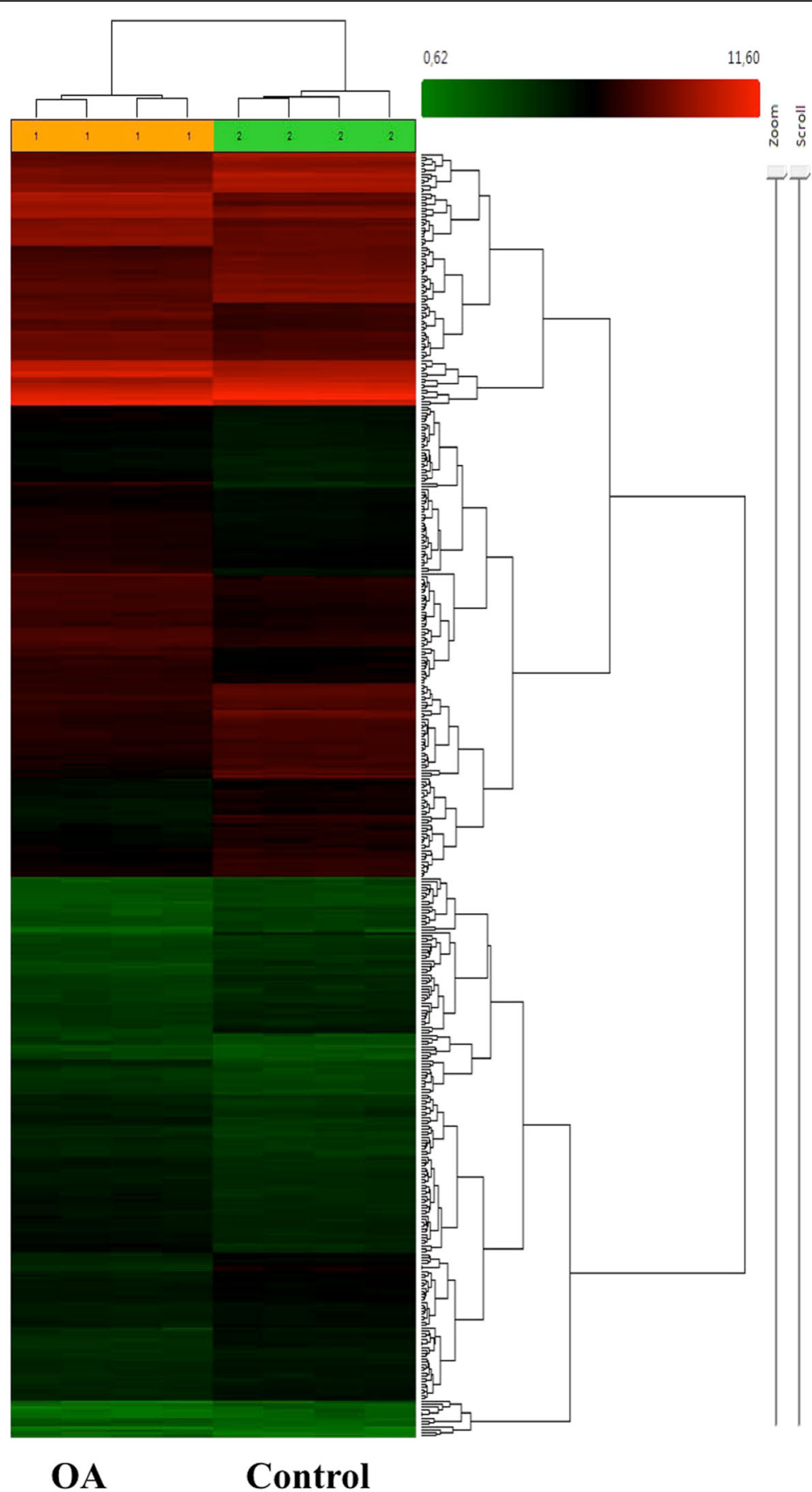

Fig. 1 Microarray analysis. The figure shows a heat map analysis of DEGs. OA treated and untreated GCs were analyzed after 8 days in culture under stimulatory conditions with FSH and IGF-1 supplementation throughout the time of culture. The cells were exposed to OA or vehicle control from day 2. Data were obtained from four samples in each group

development", "vasculature development", "cardiovascular system development", "extracellular matrix/structure organization/organization", "angiogenesis", "blood vessel morphogenesis" and "cell adhesion" (Table 2 and Supplementary Figure 2).

\section{Time dependent effects of OA on GC morphology}

After treatment with OA, cultured GCs were evaluated under a microscope $6 \mathrm{~h}, 12 \mathrm{~h}, 24 \mathrm{~h}, 48 \mathrm{~h}, 4$ days and 6 days after treatment. The cell morphology showed that OA induced morphological changed from a more 
Table 1 Top 24 DEGs affected by OA treatment of cultured GCs

\begin{tabular}{|c|c|c|c|}
\hline$\#$ & Gene Symbol & Fold change & $p$-value \\
\hline 1 & ALDH1A1 & 6.15 & 0.000001 \\
\hline 2 & ANGPTL4 & 5.69 & 2.10E-09 \\
\hline 3 & PAG11 & 4.4 & 7.01E-08 \\
\hline 4 & CD36 & 3.65 & 3.33E-08 \\
\hline 5 & SLC38A4 & 3.59 & 0.000044 \\
\hline 6 & PLA2R1 & 3.39 & 0.000014 \\
\hline 7 & KIAA1199 & 3.3 & $1.98 \mathrm{E}-08$ \\
\hline 8 & DHRS9 & 3.08 & 8.76E-07 \\
\hline 9 & LOC537017 & 2.77 & 0.000018 \\
\hline 10 & ANKRD1 & 2.73 & 1.77E-09 \\
\hline 11 & CD44 & 2.73 & 5.76E-07 \\
\hline 12 & EFEMP1 & 2.69 & 3.33E-07 \\
\hline 13 & CYP19A1 & -4.68 & 0.000004 \\
\hline 14 & $\mathrm{CNIH3}$ & -4.03 & 4.60E-08 \\
\hline 15 & JAK3 & -3.38 & 2.94E-08 \\
\hline 16 & $T L L 2$ & -3.31 & 2.66E-07 \\
\hline 17 & $\mathrm{CDH} 2 \mathrm{O}$ & -3.07 & 0.000004 \\
\hline 18 & SUSD 4 & -2.91 & 0.000003 \\
\hline 19 & NOS2 & -2.9 & 2.63E-07 \\
\hline 20 & AFMID & -2.87 & $6.78 \mathrm{E}-07$ \\
\hline 21 & QRFPR & -2.77 & 2.00E-06 \\
\hline 22 & $S L C 28 A 2$ & -2.76 & 2.40E-05 \\
\hline 23 & $C M B L$ & -2.71 & 2.00E-06 \\
\hline 24 & KCND2 & -2.68 & 1.40E-05 \\
\hline
\end{tabular}

DEGs Differentially expressed genes, GCs Granulosa cells, OA Oleic acid

fibroblast-like to a foam-cell-like structure in a time dependent manner (Fig. 4). In a previous study, we could show that this morphological change is mainly due to considerable lipid droplet accumulation [17].

\section{Discussion}

Bioinformatic analysis of DEGs by IPA suggests that various upstream regulators were affected by OA treatment in cultured bovine GCs. Most interesting, FSH and NR5A1 (also known as steroidogenic factor 1, SF-1) were among the inhibited regulators. Both factors and associated pathways are known to play significant roles during folliculogenesis [20-23]. Down-regulation of FSH signaling is in line with our previously published data indicating that in particular the abundance of FSHR transcripts and thus the corresponding pathways and genes are down regulated by OA treatment [17]. This may result in the observed prevention of up-regulation of the functional key genes CYP19A1, CCND2, LHCGR and $I N H A$ and of E2 production from day 4 to the end of the experiment (see Fig. 3). In addition to this, also Over-Representation Analysis of down-regulated genes revealed that most of these are involved in female reproduction related processes such as "reproductive structure/system development", "ovulation cycle process", "(positive) regulation of follicle-stimulating hormone/gonadotropin (secretion)" (see Table 2). Thus, these data indicate that the presence of OA compromised GC functionality and suggest that OA may impair folliculogenesis and the ovarian cycle in cows. This is also supported by the observation of morphological changes in OA treated GCs showing lipid droplet accumulation. Also in human lipid droplet accumulation in GCs have been correlated with fertility problems [24]. Also recent in vivo data suggest that increased NEFA levels and in particular increased OA concentrations in the follicular fluid have detrimental effects on follicle growth and even prevent ovulation [18, 25]. However, the role of OA seems complex and is still controversial. Some studies also clearly demonstrated positive effects on oocytes and during early embryo development as well as protective actions against lipotoxicity [26, 27].

Among the activated upstream regulators the most interesting were TGFB1, Cg (choriogonadotropin), Tgf beta, NFkB, HIF1A, EDN1 and WNT3A (see Supplementary Table 2). The significant activation of the $\mathrm{Cg}$ pathway suggests that LH signaling was induced by increased OA concentrations via the luteinizing hormone/ choriogonadotropin receptor (LHCGR) pathway. Together with the down-regulated GC functionality, this suggests that the cells are driven towards luteinization. In vivo the preovulatory LH surge induces a rapid and profound molecular transformation of follicular cells termed luteinization in particular in GCs [28-30]. These changes (down-regulation of E2 production and of follicular marker transcripts) seem to be at least partly mimicked by OA in cultured GCs. However, this transformation is certainly not complete. Luteinization of GCs is not only associated with down-regulation of E2 but in addition with up-regulation of progesterone (P4) production. This has been clearly shown in vivo after the preovulatory LH surge $[28,31]$. However, we could show in our previous studies that OA treatment of cultured GCs is clearly associated with decreased E2 but not with increased P4 production. Contrary, P4 production was even down-regulated $[17,18]$.

Interestingly, also TGFB1, Tgf beta, NFkB, HIF1A and WNT3A were indicated as activated by OA treatment. According to previous studies these factors and associated pathways are involved in the regulation of the Epithelial-to-Mesenchymal Transition (EMT) in several cell types including ovarian cells [32]. Activation of these regulators thus suggests EMT up-regulation by OA treatment. Partial EMT is a characteristic feature of GCs entering the folliculo-luteal transformation [33]. It is also quite noticeable that EDN1 is among the activated 


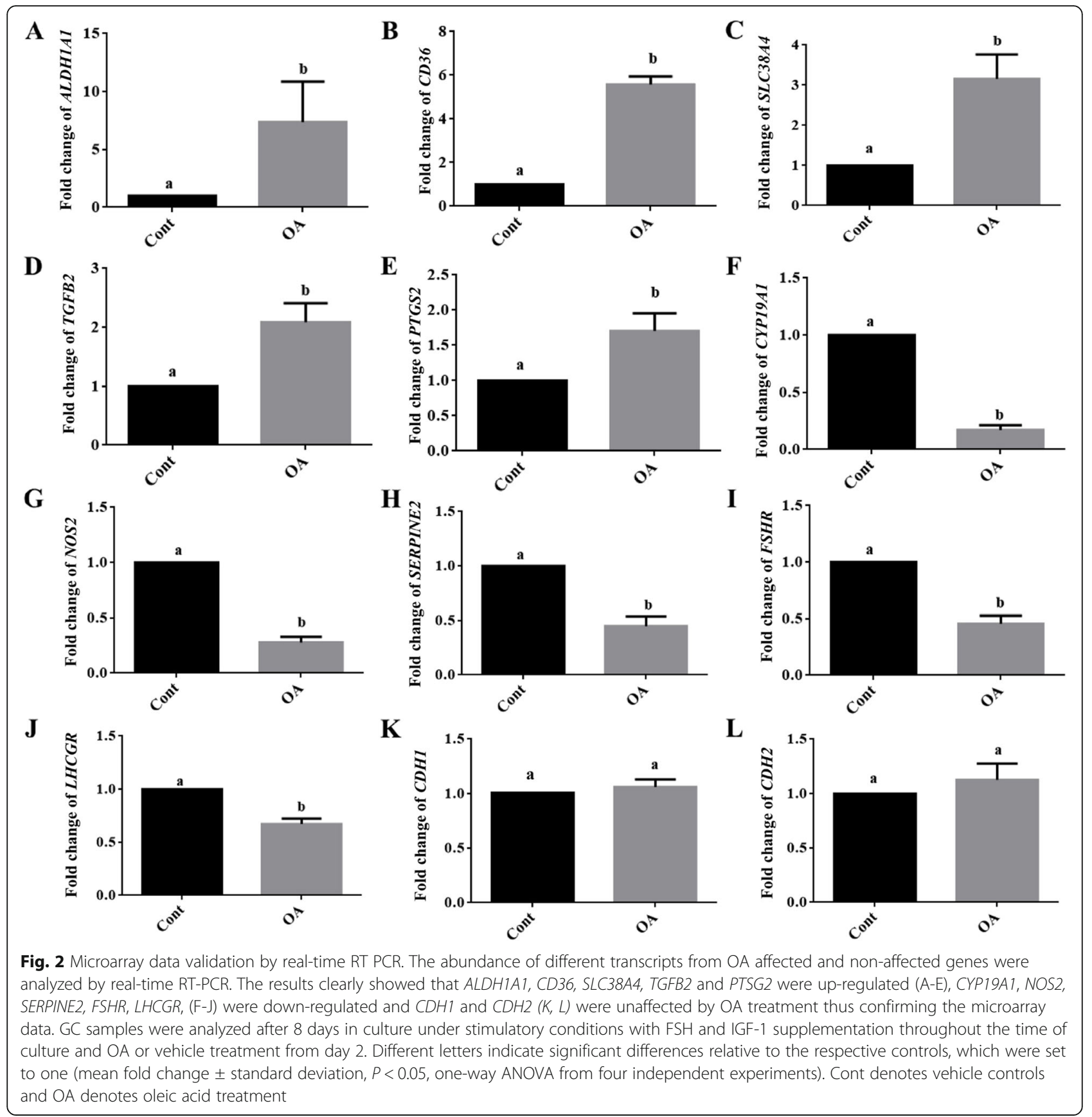

upstream regulators. On one hand, endothelins are known to be involved in angiogenic processes [34-36] and on the other hand, the formation of new vasculature is an essential feature of the developing corpus luteum $[37,38]$. EDN1, EDN2 and EDN3 as well as endothelin receptors type A and B (EDNRA, ENDRB) are present in bovine GCs [39] as well as in our cultured GCs whereby EDNRA is significantly down- and ENDRB significantly up-regulated (see Supplementary Table 2). Taken together, down-regulation of GC functionality and simultaneous activation of the endothelin pathway and of GO terms related to angiogenesis, vascularization and morphogenic processes (e.g. Anatomical structure formation, Extracellular structure/matrix organization, see Table 2) support our hypothesis that OA treatment induces a luteal-like transformation in cultured GCs. Not least, also the observed lipid droplet accumulation in OA treated cells suggests their more luteal-like character since lipid droplets are a major feature of steroidogenic luteal cells [40].

Intriguingly, IPA analysis of affected "Canonical Pathways" and "Cell functions and Diseases" provided also 


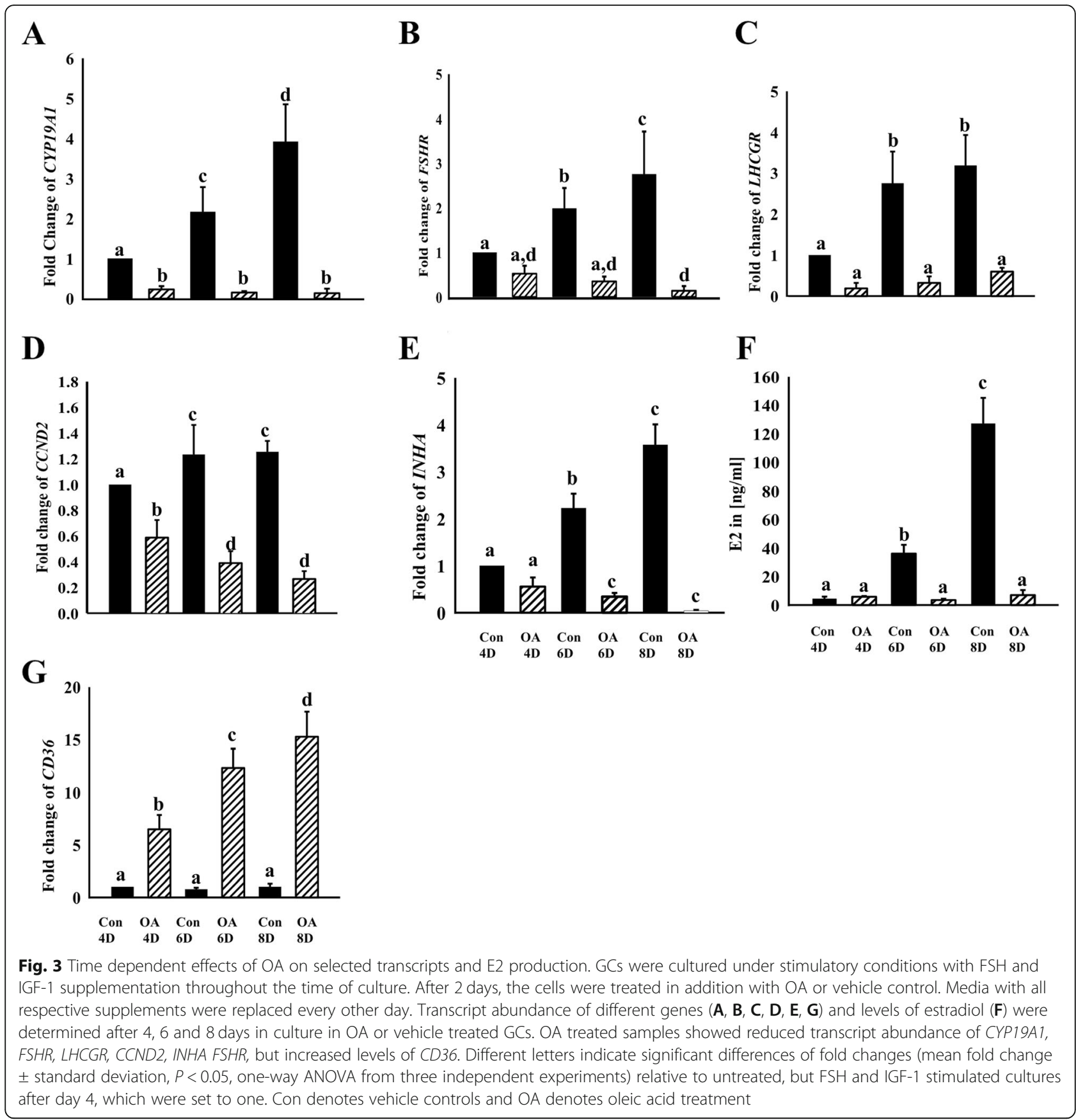

evidence that cancer-related signaling might be promoted by OA treatment (see Supplementary Tables 3 and 4). In addition, the up-regulation of genes involved in angiogenic and morphogenic processes can be interpreted as supportive of the alternative hypothesis that increased OA concentrations facilitate tumor initiation and progression. However, cancer studies are certainly overrepresented in databases used by IPA and other bioinformatic tools. This may lead to a biased output favoring pathway and regulators involved in cancerogenesis. In addition, the observed prevalence of GC cancer in cattle is very low $(0.5-0.75 \%)$ according to several studies $[41,42]$. Accordingly, this interpretation of our data must be treated with caution and certainly needs additional experimental evidence.

\section{Conclusions}

Based on our results and on studies from previous reports we propose that OA induces fatty acid uptake and lipid droplet accumulation in GCs and may inhibit FSH signaling and affect the expression of many genes, which are involved in GC functionality. On the other hand, 
Table 2 Affected Gene Ontology (GO) terms according to WebGestalt Over-Representation Analysis

\begin{tabular}{|c|c|c|c|c|}
\hline Regulation & GO & Name & gNum & FDR \\
\hline Down & 0048608 & Reproductive structure development & 16 & $1.21 \mathrm{E}-02$ \\
\hline Down & 0061458 & Reproductive system development & 16 & $1.21 \mathrm{E}-02$ \\
\hline Down & 0048468 & Cell development & 39 & $1.21 \mathrm{E}-02$ \\
\hline Down & 0003006 & Developmental process involved in reproduction & 19 & 2.32E-02 \\
\hline Down & 0022602 & Ovulation cycle process & 7 & 2.32E-02 \\
\hline Down & 0046880 & Regulation of follicle-stimulating hormone secretion & 3 & 2.32E-02 \\
\hline Down & 0046881 & Positive regulation of follicle-stimulating hormone & 3 & 2.32E-02 \\
\hline Down & 0007167 & Enzyme linked receptor protein signaling pathway & 24 & 2.82E-02 \\
\hline Down & 0032278 & Positive regulation of gonadotropin secretion & 3 & 2.82E-02 \\
\hline Down & 0046884 & Follicle-stumulating hormone secretion & 3 & 2.82E-02 \\
\hline Up & 0072359 & Circulatory system development & 42 & 4.61E-10 \\
\hline Up & 0048646 & Anatomical structure formation involved in morphogenesis & 39 & $6.32 \mathrm{E}-08$ \\
\hline Up & 0001944 & Vasculature development & 30 & 9.44E-08 \\
\hline Up & 0072358 & Cardiovascular system development & 30 & 9.82E-08 \\
\hline Up & 0043062 & Extracellular structure organization & 22 & 1.24E-07 \\
\hline Up & 0030198 & Extracellular matrix organization & 22 & 1.24E-07 \\
\hline Up & 0009888 & Tissue development & 53 & 1.45E-07 \\
\hline Up & 0001525 & Angiogenesis & 24 & 1.82E-07 \\
\hline Up & 0048514 & Blood vessel morphogenesis & 26 & 2.48E-07 \\
\hline Up & 0007155 & Cell adhesion & 50 & 7.64E-07 \\
\hline
\end{tabular}

genes and pathways involved in angiogenic and morphogenic processes are up-regulated thus suggesting that $\mathrm{OA}$ may activate pathways favoring folliculo-luteal transition.

\section{Methods}

\section{Culture of granulosa cells}

Isolation and culture of GCs were done as previously described [17, 43, 44]. Briefly, bovine ovaries were collected from a commercial slaughterhouse (Danish Crown Teterower Fleisch GmbH, Teterow). GCs were aspirated from small to medium follicles (2-6 $\mathrm{mm}$ diameter) that contain clear antral fluid with an 18-gauge needle in PBS with antibiotics. The percentage of viable cells was determined in a hemocytometer by using the trypan blue exclusion method. Routinely, $1.25 \times 10^{5}$ viable cells were seeded on 24-well collagen R (Serva, Heidelberg, Germany) coated plates per $0.5 \mathrm{ml}$ of basal $\alpha$-MEM (Merck/Biochrom, Berlin, Germany) without serum but supplemented with $25 \mathrm{ng} / \mathrm{ml}$ IGF-1, $20 \mathrm{ng} / \mathrm{ml}$ FSH and $2 \mu \mathrm{M}$ androstenedione (Sigma Aldrich, Steinheim, Germany) to induce E2 production. Conditioned media were replaced with fresh media including all respective supplements every other day. Two days after seeding $400 \mu \mathrm{M}$ of OA (Sigma Aldrich, Steinheim, Germany) dissolved in ethanol as described earlier [17] was added with the first change of media (i.e. after 2 days in culture). The concentration of $400 \mu \mathrm{M}$ was selected, because similar levels have been found in vivo under NEB conditions and this concentration has been also shown to efficiently affect gene expression and hormone production in GCs $[11,17]$. To allow the cells to recover from plating stress and to re-acquire GClike morphological and physiological features (expression of marker genes and E2 production) the cells were cultured for 8 days [44] for microarray analysis. In addition, early alterations of the abundance of selected marker transcripts and of E2 concentrations in spent media were also studied after 4, 6 and 8 days. Early morphological changes were analyzed $6 \mathrm{~h}, 12 \mathrm{~h}, 24 \mathrm{~h}, 48 \mathrm{~h}, 4$ th day and 6 th day after addition of OA by using a Nikon TMS-F inverted microscope.

\section{RNA isolation and CDNA synthesis}

RNA isolation and cDNA synthesis was done as previously described [19]. Briefly, RNA was isolated with the Nucleo $\operatorname{Spin}^{\circ}$ RNA II Kit (Macherey-Nagel, Düren, Germany) and quantified with a NanoDrop1000 Spectrophotometer (Thermo Scientific, Bonn, Germany). The cDNA for real-time RT-PCR was prepared by using the SensiFAST cDNA Synthesis Kit (Bioline, Luckenwalde, Germany) from 200 ng RNA. 


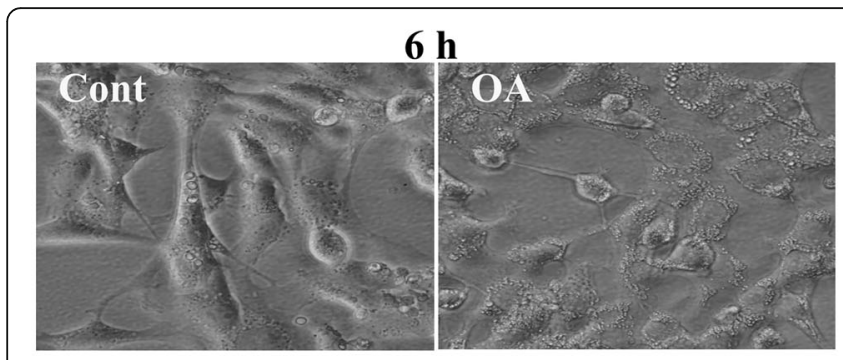

$24 \mathrm{~h}$

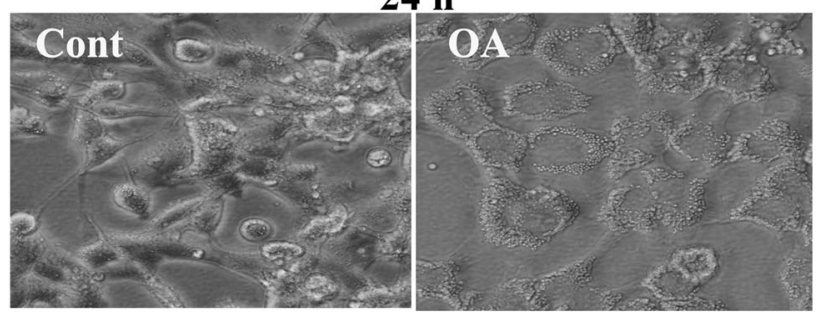

4 days
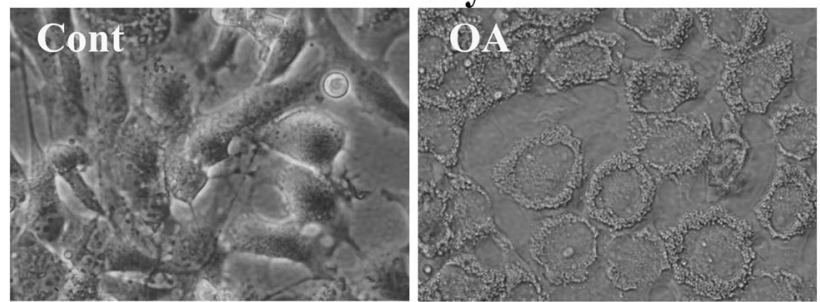

$12 \mathrm{~h}$
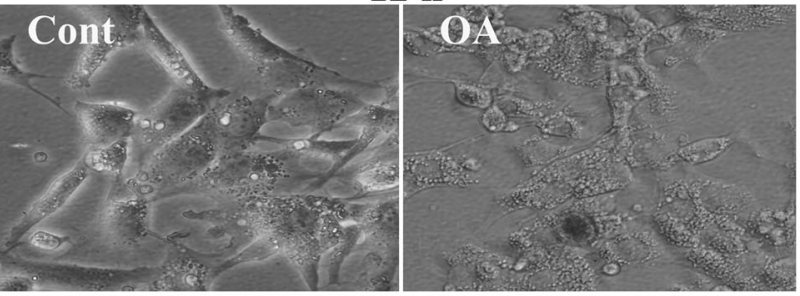

$48 \mathrm{~h}$

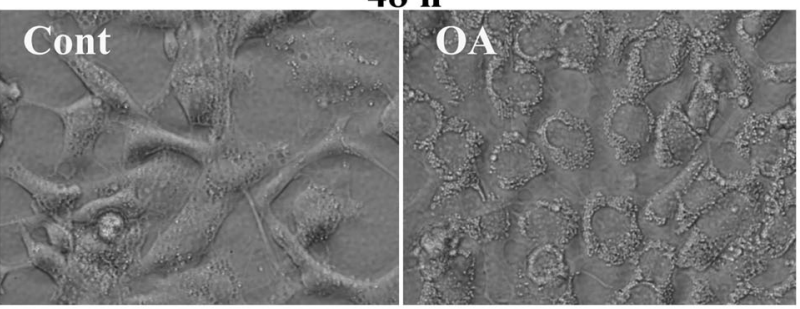

6 days

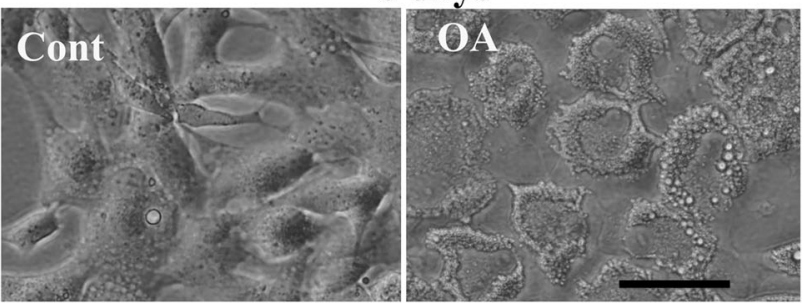

Fig. 4 Time dependent morphological changes of GCs after OA treatment. Following 2 days of stimulatory culture conditions with FSH and IGF-1 supplementation GCs were treated with OA or vehicle control in addition and photographed $6 \mathrm{~h}, 12 \mathrm{~h}, 24 \mathrm{~h}, 48 \mathrm{~h}, 4 \mathrm{~d}$ and 6 later to study the OA induced changes of morphological features. A continuous change of the morphology from a fibroblast-like towards a flat, foam cell-like morphology can be seen. Cont denotes vehicle controls and OA denotes oleic acid treated cells. Scale bar =50 $\mu m$

\section{Microarray analysis}

For mRNA microarray analysis RNA Integrity Numbers (RIN) were determined in a Bioanalyzer System (Agilent Technologies Inc.). Numbers were 9.7 on average in both experimental groups (OA treated and vehicle treated GCs, 4 samples per group) ranging from 9.6 to 10.0. Total RNA of the different samples was hybridized on Bovine Gene 1.0 ST Array (Affymetrix, St. Clara, CA, USA). Amplification, labelling and hybridization was performed with the "GeneChip Expression 3' Amplification One-Cycle Target Labeling and Control Reagents" (Affymetrix) according to the manufacturer's protocol. Hybridization was done overnight in the GeneChipR Hybridization Oven (Affymetrix) and visualized with the Affymetrix GeneChip Scanner 3000. Raw data were processed with the Expression Console (V1.4.1.46; Affymetrix). Normalization, background reduction and a gene-level summary was done using the RMA method (Robust Multichip Average). Results of the array have been submitted to the GEO database (GSE152307). Subsequent analysis was done with the Transcriptome Analysis Console 3.0 (TAC3.0, Affymetrix) to check for differentially expressed genes under different conditions. Analysis of Variance (ANOVA) was used to calculate the $p$-value and was additionally corrected for FDR (False Discovery Rate, Benjamini-Hochberg method) integrated in TAC3.0. Levels of significance for differentially expressed genes were set at fold change $(\mathrm{FC})>|1.5|$, ANOVA $p<0.05$ and FDR $<0.05$.

\section{Real-time RT-PCR}

Validation of microarray data was carried out by analysing the transcript abundance of four up-regulated (ALDH1A1, CD36, SLC38A4, TGFB2 and PTSG2), four down-regulated (CYP19A1, NOS2, SERPINE2, FSHR, $L H C G R)$ and two unchanged genes (CDH1 and CDH2) by real time RT-PCR. For this, 0.25 and $0.5 \mu \mathrm{l}$ CDNA of each sample were amplified using SensiFastTM SYBR No-ROX (Bioline, Luckenwalde, Germany) and genespecific primers (Supplementary Table 5) in a LightCycler 96 instrument (Roche). To ensure amplification of the correct products melting points of products were routinely analysed. Initially, all amplicons were cloned and sequenced. These cloned plasmids were used as external standards. For preparation of an external standard curve, five fresh dilutions were prepared with concentrations from $5 \times 10^{12}$ to $5 \times 10^{16} \mathrm{~g} \mathrm{DNA} /$ reaction. These were co-amplified with each run of samples. After 
amplification, values of 0.25 and $0.5 \mu \mathrm{l}$ of cDNA were averaged considering different dilutions. The size of products was routinely controlled by agarose gel electrophoresis. For normalization, the abundance of target transcripts was divided by the corresponding abundance of TBP housekeeping control transcripts [45].

\section{Bioinformatic analysis of differentially expressed genes}

To identify "Upstream Regulators", "Canonical Pathways", and "Functions and Diseases" affected by OA treatment, differentially expressed genes (DEGs) were analyzed by the Ingenuity Pathway Analysis tool (IPA, QIAGEN, Hilden, Germany). In addition to this, gene enrichment and gene ontology analysis was done with the WEB-based GEneSeTAnaLysis Toolkit (WebGestalt).

\section{Quantification of 17- $\beta$-estradiol}

The levels of E2 in conditioned media collected at different days after OA treatment were estimated with an ultrasensitive 125I-RIA (DSL, Sinsheim, Germany) in $200-\mu \mathrm{L}$ duplicates. The standard curve was established between 0.005 and 0.750 ngmL- 1 . Radioactivity was measured with an automatic gamma counter with integrated RIA calculation (Wizard; Perkin Elmer, Rodgau, Germany). The detection limit of the method was found at $0.003 \mathrm{ngmL}-1$. The intra- and inter-assay CVs were 8.8 and 9.7\%, respectively. The analysis of media was done with $10 \mu \mathrm{l}$ of the undiluted sample in duplicates as also described in previous studies $[17,46]$.

\section{Statistical analysis}

All experiments were carried out at least three times independently. Comparative data from OA effects on transcript abundance at different days were analysed by oneway analysis of variance (ANOVA) using the HolmSidak all pairwise multiple comparison procedure with the Sigma Plot 11.0 Statistical Analysis System (Jandel Scientific, San Rafael, CA, USA). Microarray reevaluation data at the 8th day in culture were analysed by the paired t-test using the GraphPad prism 5.0 software. $P$ values $<0.05$ were considered significant.

\section{Abbreviations \\ DEG: Differentially Expressed Gene; E2: 17- $\beta$-Estradiol; EMT: Epithelial-to- Mesenchymal Transition; FFA: Free Fatty Acid; FSH: Follicle Stimulating Hormone; GC: Granulosa Cell; GO: Gene Ontology; IGF-1: Insulin-like-Growth Factor 1; IPA: Ingenuity Pathway Analysis; LH: Luteinizing Hormone; NEB: Negative Energy Balance; NEFA: Non-Esterified Fatty Acid; OA: Oleic Acid; P4: Progesterone; PA: Palmitic Acid; SA: Stearic Acid}

\section{Supplementary Information}

The online version contains supplementary material available at https://doi. org/10.1186/s12864-021-07817-6.

Additional file 1: Figure S1. GO terms associated with $O A$ downregulated genes according to WebGestalt (significantly affected GO term in red).
Additional file 2: Figure S2. GO terms associated with OA upregulated genes according to WebGestalt (significantly affected GO term in red).

Additional file 3: Table S1. List of OA regulated genes (DEGs).

Additional file 4: Table S2. OA regulated Upstream Regulators according to IPA analysis.

Additional file 5: Table S3. OA regulated Canonical Pathways according to IPA analysis.

Additional file 6: Table S4. OA regulated Diseases and Functions according to IPA analysis.

Additional file 7: Table S5. List of primers used for transcript quantification by real-time RT-PCR.

\section{Acknowledgements}

We thank Veronica Schreiter, Maren Anders and Ildiko Toth for their excellent technical assistance. We also thank and the Department of Animal Biology, School of Life Sciences, University of Hyderabad for providing technical facilities.

\section{Authors' contributions}

VRY designed and conducted the experiments and wrote the manuscript. DK did the mRNA microarray analysis and JV contributed to the experimental design and preparation of the manuscript. All authors have read and approved the manuscript.

\section{Funding}

This study was funded by the core budget of the Leibniz Institute for Farm Animal Biology (FBN). VRY was supported by the DST-Inspire Faculty program (DST-India). Open Access funding enabled and organized by Projekt DEAL.

\section{Availability of data and materials}

The datasets generated and/or analysed during the current study are available in the GEO repository, https://www.ncbi.nlm.nih.gov/geo/query/acc. cgi?acc=GSE152307

Primers for Real -time RT-PCR analysis were designed from published sequences with accession Nos: NM_174239.2, NM_001076372, NM_001278621.1, NM_001002763.1, NM_001166492.1, NM_174445, NM_174305, NM_174061, NM_174381, NM_174094.4, NM_001076799.1، NM_174669.2, NM_001205943.1, NM_001113252.1, NM_001075742.1.

\section{Declarations}

Ethics approval and consent to participate

Not applicable.

\section{Consent for publication}

Not applicable.

\section{Competing interests}

The authors declare that they have no competing interests

\section{Author details}

'Animal Biology Department, School of Life Sciences, University of Hyderabad, Hyderabad, Telagana, India. Institute for Immunology, University of Rostock, 18055 Rostock, Germany. Institute of Reproductive Biology, Leibniz Institute for Farm Animal Biology (FBN), Wilhelm-Stahl-Allee 2, 18196 Dummerstorf, Germany.

Received: 26 August 2020 Accepted: 14 June 2021

Published online: 29 June 2021

References

1. Van Hoeck V, Leroy JL, Alvarez AM, Rizos D, Gutierrez-Adan A, Schnorbusch $K$, et al. Oocyte developmental failure in response to elevated nonesterified fatty acid concentrations: mechanistic insights. Reproduction. 2013;145(1): 33-44.

2. Jorritsma R, Wensing T, Kruip TA, Vos PL, Noordhuizen JP. Metabolic changes in early lactation and impaired reproductive performance in dairy cows. Vet Res. 2003;34(1):11-26. 
3. Leroy J, Vanholder T, Mateusen B, Christophe A, Opsomer G, de Kruif A, et al. Non-esterified fatty acids in follicular fluid of dairy cows and their effect on developmental capacity of bovine oocytes in vitro. Reproduction. 2005;130(4):485-95.

4. Holte J, Bergh T, Berne $C$, Lithell $H$. Serum lipoprotein lipid profile in women with the polycystic ovary syndrome: relation to anthropometric, endocrine and metabolic variables. Clin Endocrinol. 1994;41(4):463-71.

5. Niu Z, Lin N, Gu R, Sun Y, Feng Y. Associations between insulin resistance, free fatty acids, and oocyte quality in polycystic ovary syndrome during in vitro fertilization. J Clin Endocrinol Metab. 2014;99(11):E2269-76.

6. Calonge RN, Kireev R, Guijarro A, Cortes S, Andres C, Caballero P. Lipid dysregulation in seminal and follicular fluids could be related with male and female infertility. Endocrinol Metab Int J. 2018;6:7.

7. Rukkwamsuk T, Geelen MJ, Kruip TA, Wensing T. Interrelation of fatty acid composition in adipose tissue, serum, and liver of dairy cows during the development of fatty liver postpartum. J Dairy Sci. 2000;83(1):52-9.

8. Esposito G, Irons PC, Webb EC, Chapwanya A. Interactions between negative energy balance, metabolic diseases, uterine health and immune response in transition dairy cows. Anim Reprod Sci. 2014;144(3-4):60-71.

9. Moyes KM, Drackley JK, Salak-Johnson JL, Morin DE, Hope JC, Loor JJ. Dietary-induced negative energy balance has minimal effects on innate immunity during a streptococcus uberis mastitis challenge in dairy cows during midlactation. J Dairy Sci. 2009;92(9):4301-16.

10. Staples CR, Thatcher WW, Clark JH. Relationship between ovarian activity and energy status during the early postpartum period of high producing dairy cows. J Dairy Sci. 1990;73(4):938-47.

11. Aardema H, Lolicato F, van de Lest $C H$, Brouwers JF, Vaandrager AB, van Tol $H T$, et al. Bovine cumulus cells protect maturing oocytes from increased fatty acid levels by massive intracellular lipid storage. Biol Reprod. 2013;88(6):164.

12. Duplus $\mathrm{E}$, Forest $\mathrm{C}$. Is there a single mechanism for fatty acid regulation of gene transcription? Biochem Pharmacol. 2002;64(5-6):893-901.

13. Nakamura MT, Cheon Y, Li Y, Nara TY. Mechanisms of regulation of gene expression by fatty acids. Lipids. 2004;39(11):1077-83.

14. Georgiadi A, Kersten S. Mechanisms of gene regulation by fatty acids. Adv Nutr. 2012;3(2):127-34.

15. Mu YM, Yanase T, Nishi Y, Tanaka A, Saito M, Jin CH, et al. Saturated FFAs, palmitic acid and stearic acid, induce apoptosis in human granulosa cells. Endocrinology. 2001:142(8):3590-7.

16. Vanholder T, Leroy JL, Soom AV, Opsomer G, Maes D. Coryn M, de KA: effect of non-esterified fatty acids on bovine granulosa cell steroidogenesis and proliferation in vitro. Anim Reprod Sci. 2005;87(1-2):33-44.

17. Yenuganti VR, Viergutz T, Vanselow J. Oleic acid induces specific alterations in the morphology, gene expression and steroid hormone production of cultured bovine granulosa cells. Gen Comp Endocrinol. 2016:232:134-44.

18. Sharma A, Baddela VS, Becker F, Dannenberger D, Viergutz T, Vanselow J. Elevated free fatty acids affect bovine granulosa cell function: a molecular cue for compromised reproduction during negative energy balance. Endocr Connect. 2019;8(5):493-505.

19. Yenuganti VR, Vanselow J. Oleic acid induces down-regulation of the granulosa cell identity marker FOXL2, and up-regulation of the Sertoli cell marker SOX9 in bovine granulosa cells. Reprod Biol Endocrinol. 2017;15(1):57.

20. Pelusi C, Ikeda Y, Zubair M, Parker KL. Impaired follicle development and infertility in female mice lacking steroidogenic factor 1 in ovarian granulosa cells. Biol Reprod. 2008;79(6):1074-83.

21. Jeyasuria $P$, Ikeda $Y$, Jamin SP, Zhao LP, De Rooij DG, Themmen APN, et al. Cell-specific knockout of steroidogenic factor 1 reveals its essential roles in gonadal function. Mol Endocrinol. 2004;18(7):1610-9.

22. Casarini L, Crépieux P. Molecular mechanisms of action of FSH. Front Endocrinol (Lausanne). 2019:10:305

23. Ilha GF, Rovani MT, Gasperin BG, Antoniazzi AQ, Gonçalves PB, Bordignon V, et al. Lack of FSH support enhances LIF-STAT3 signaling in granulosa cells of atretic follicles in cattle. Reproduction. 2015;150(4):395-403.

24. Raviv S, Hantisteanu S, Sharon SM, Atzmon Y, Michaeli M, Shalom-Paz E. Lipid droplets in granulosa cells are correlated with reduced pregnancy rates. J Ovarian Res. 2020;13(1):4.

25. Ferst JG, Missio D, Bertolin K, Gasperin BG, Leivas FG, Bordignon V, et al. Intrafollicular injection of nonesterified fatty acids impaired dominant follicle growth in cattle. Anim Reprod Sci. 2020;219:11.

26. Aardema H, Vos PL, Lolicato F, Roelen BA, Knijn HM, Vaandrager AB, et al. Oleic acid prevents detrimental effects of saturated fatty acids on bovine oocyte developmental competence. Biol Reprod. 2011;85(1):62-9.
27. Fayezi S, Leroy J, Novin MG, Darabi M. Oleic acid in the modulation of oocyte and preimplantation embryo development. Zygote. 2018;26(1):1-13.

28. Nimz M, Spitschak M, Schneider F, Fürbass R, Vanselow J. Down-regulation of genes encoding steroidogenic enzymes and hormone receptors in late preovulatory follicles of the cow coincides with an accumulation of intrafollicular steroids. Domest Anim Endocrinol. 2009;37:45-54.

29. Gilbert I, Robert C, Dieleman S, Blondin P, Sirard MA. Transcriptional effect of the LH surge in bovine granulosa cells during the peri-ovulation period. Reproduction. 2011;141(2):193-205.

30. Christenson LK, Gunewardena S, Hong X, Spitschak M, Baufeld A, Vanselow J. Research resource: preovulatory LH surge effects on follicular theca and granulosa transcriptomes. Mol Endocrinol. 2013;27(7):1153-71.

31. Berisha B, Steffl M, Amselgruber W, Schams D. Changes in fibroblast growth factor 2 and its receptors in bovine follicles before and after $\mathrm{GnRH}$ application and after ovulation. Reproduction. 2006;131(2):319-29.

32. Bilyk O, Coatham M, Jewer M, Postovit LM. Epithelial-to-mesenchymal transition in the female reproductive tract: from Normal functioning to disease pathology. Front Oncol. 2017;7:145.

33. Childs AJ, McNeilly AS. Epithelial-to-mesenchymal transition in granulosa cells: a key to activation of follicle growth? Biol Reprod. 2012;86(5):152 151-152.

34. Rosanò L, Spinella F, Bagnato A. Endothelin 1 in cancer: biological implications and therapeutic opportunities. Nat Rev Cancer. 2013;13(9): 637-51.

35. Wu MH, Huang CY, Lin JA, Wang SW, Peng CY, Cheng HC, et al. Endothelin1 promotes vascular endothelial growth factor-dependent angiogenesis in human chondrosarcoma cells. Oncogene. 2014;33(13):1725-35.

36. Bagnato A, Spinella F. Emerging role of endothelin-1 in tumor angiogenesis. Trends Endocrinol Metab. 2003;14(1):44-50.

37. Schams D, Berisha B. Angiogenic factors (VEGF, FGF and IGF) in the bovine corpus luteum. J Reprod Dev. 2002;48(3):233-42.

38. Zheng J, Redmer DA, Reynolds LP. Vascular development and heparinbinding growth-factors in the bovine corpus-luteum at several stages of the estrous-cycle. Biol Reprod. 1993;49(6):1177-89.

39. Bridges PJ, Cho J, Ko C. Endothelins in regulating ovarian and oviductal function. Front Biosci (Schol Ed). 2011;3:145-55.

40. Talbott HA, Plewes MR, Krause C, Hou X, Zhang P, Rizzo WB, et al. Formation and characterization of lipid droplets of the bovine corpus luteum. Sci Rep. 2020;10(1):11287.

41. Pérez-Martínez C, Durán-Navarrete AJ, García-Fernández RA, EspinosaAlvarez J, Escudero Diez A, García-Iglesias MJ. Biological characterization of ovarian granulosa cell tumours of slaughtered cattle: assessment of cell proliferation and oestrogen receptors. J Comp Pathol. 2004;130(2-3):117-23.

42. Zemjanis R, Larson LL, Bhalla RP. Clinical incidence of genital abnormalities in the cow. J Am Vet Med Assoc. 1961;139:1015-8.

43. Baufeld A, Vanselow J. A tissue culture model of estrogen-producing primary bovine granulosa cells. J Vis Exp. 2018;139:1.

44. Yenuganti VR, Vanselow J. Cultured bovine granulosa cells rapidly lose important features of their identity and functionality, but partially recover under long term culture conditions. Cell Tissue Res. 2017;368(2):397.

45. Baddela VS, Baufeld A, Yenuganti VR, Vanselow J, Singh D. Suitable housekeeping genes for normalization of transcript abundance analysis by real-time RT-PCR in cultured bovine granulosa cells during hypoxia and differential cell plating density. Reprod Biol Endocrinol. 2014;12(1):118.

46. Schneider F, Brüssow KP. Effects of a preovulatory administered depot gonadotrophin-releasing hormone agonist on reproductive hormone levels and pregnancy outcome in gilts. Reprod Fertil Dev. 2006;18(8):857-66.

\section{Publisher's Note}

Springer Nature remains neutral with regard to jurisdictional claims in published maps and institutional affiliations. 